\title{
Comparison of Disease Nature of MERS, SARS-CoV-1, and SARS-CoV-2:
}

\section{A Review}

\author{
Sandra El Hajj ${ }^{1, *}$, Yonna Sacre ${ }^{2}$, Elie K Barbour ${ }^{1,3,4}$, Taha Kumosani ${ }^{5}$, Gilles Amr ${ }^{1}$, Wael Karameh ${ }^{1}$, Mira Daher ${ }^{2}$, and Dany \\ Farah $^{2}$
}

${ }^{1}$ The American Preventive Health Organization, Miami, Florida, USA

${ }^{2}$ Nutrition and Food Sciences Department, Faculty of Arts and Sciences, Holy Spirit University of Kaslik, Lebanon

${ }^{3}$ Biochemistry Department, King Abdulaziz University, Kingdom of Saudi Arabia

${ }^{4}$ Director of R \& D Department, Opticon Co., Switzerland

${ }^{5}$ Department of Biochemistry, Faculty of Science, Experimental Biochemistry Unit, King Fahd Medical Research Center and Production of Bioproducts for Industrial Applications Research Group, King Abdulaziz University, Kingdom of Saudi Arabia

*Corresponding author: Sandra El Hajj, Founder and President of the American Preventive Health Organization, Miami, Florida, USA, E-mail: sandra_elhage@hotmail.com

Received: 25 Mar, 2021 | Accepted: 31 May, 2021 | Published: 15 Jun, 2021

Citation: El Hajj S, Sacre Y, Barbour EK, Kumosani T, Amr G, et al. (2021) Comparison of Disease Nature of MERS, SARS-CoV-1, and SARSCoV-2: A Review. J Emerg Dis Virol 6(2): dx.doi.org/10.16966/2473-1846.163

Copyright: (C) $2021 \mathrm{El} \mathrm{Hajj} \mathrm{S,} \mathrm{et} \mathrm{al.} \mathrm{This} \mathrm{is} \mathrm{an} \mathrm{open-access} \mathrm{article} \mathrm{distributed} \mathrm{under} \mathrm{the} \mathrm{terms} \mathrm{of} \mathrm{the} \mathrm{Creative} \mathrm{Commons} \mathrm{Attribution} \mathrm{License,}$ which permits unrestricted use, distribution, and reproduction in any medium, provided the original author and source are credited.

\section{Abstract}

Background: The lockdown imposed during the waves of SARS-CoV-2, also known as COVID-19, had several consequences on nations at many levels including economic, sociocultural, health and political. The vast majority of countries have been profoundly impacted, despite the widespread of vaccination initiatives all over the countries. With lockdowns still imposed on some European and west Asian countries, it's still unknown how long SARS-CoV-2 will carry on with its burden on society. The future is indefinite.

Aim: The aim of this study is to project the possible effects of SARS-CoV-2 on society and its future path based on our previous accumulated knowledge of two different types of coronaviruses that impacted societies in past years: SARS-CoV-1 and MERS. This study aims at helping healthcare providers, in both developed and developing countries understand the differences and similarities between these three coronavirus types and update their knowledge in order to establish better guidelines related to this novel pandemic that we expect to turn endemic.

Methods: Several well-founded researches were published about SARS-CoV-1 and MERS. This study will retrieve and compare them in order to help predicting the path of the current SARS-CoV-2 existing now among us. Prediction will help suggest credible guidelines for health decision makers in developed and developing countries to minimize morbidities and mortalities rates while improving the quality of life of those infected.

Results: MERS, SARS-CoV-1 and SARS-CoV-2 belong to the same Betacoronavirus genus. They have many similarities in their clinical features, but differ largely in the impact on society namely the number of cases, deaths, and reproductive rates. Due to lessons learned from MERS and SARSCoV-1 and because more efficient preventive measures were hastily taken in hospitals, nosocomial infection due to SARS-CoV-2 is relatively low despite the unprecedented large number of infections.

Conclusion: Preventive measures including hand washing, social distancing and wearing face masks should be followed to slow down the transmission of the SARS-CoV-2 virus until a more comprehensive vaccination is made available to societies which would achieve the herd immunity effect. Preventive measures remain the most effective strategies to help put a halt to infection transmission until the virus gets properly controlled. Occurring mutations are rendering herd immunity more complicated since the presently approved vaccines develop antibodies against certain early types of the virus without accounting for the recent surfacing viral alterations. More studies and clinical researches are necessary. The future remains unknown.

\section{Introduction}

Viruses are among the infections that keep emerging, imposing heavy tolls on societies and their wellbeing. Coronaviruses are on top of the list as its first outbreak began with the SARS-CoV-1, followed by the MERS, and recently the SARS-CoV-2 [1].
The 2019 novel coronavirus (SARS-CoV-2) rapidly spread from its origin in Wuhan City of Hubei Province of China to the rest of the world [2]. By March 13, 2021, the disease has caused more than $119,928,590$ infections and 2,656,229 deaths. The top five countries with the highest infections are the USA (30,033,577 total infections), Brazil (11,368,316 total infections), India (11,358,644 total infections), 
Russia (4,380,535 total infections) and UK (4,253,820 total infections). Since the debut of the virus in Lebanon and within the time frame between March 2020 and March 2021, around 415,362 cases of COVID-19 (SARS-CoV-2) and 5,334 deaths have been reported [3].

Fortunately, so far, children under the age of 18 years have been infrequently affected and only account for $8.5 \%$ of the total number of cases. Among this subpopulation, very rare cases of pediatric infections led to death; but, the future course of this virus remains unknown and every month keeps unfolding new observations and findings [2].

Since SARS-CoV-2 was first identified about a year ago, thousands of mutations have occurred. This article gives a bird's eye view about this new virus. Since knowledge about it is rapidly evolving, health professionals are urged to update themselves regularly.

\section{Comparative Mini Review of the Three Diseases}

This review compares five different segments of each of the three zoonotic diseases that hit humankind throughout the past years and still: their etiology, pathogenesis, reservoirs, clinical findings, as well as their prevention and proposed treatments.

\section{Comparison of the etiology}

Coronaviruses $(\mathrm{CoV})$ are single-stranded RNA viruses that have the shape of a crown when seen under an electron microscope. They are divided into four genera including Alfacoronavirus (AlfaCoV), Betacoronavirus (BetaCoV), Deltacoronavirus, and Gammacoronavirus. While bats and rodents constitute the gene source of AlfaCoV and BetaCoV, avian species constitute the gene source of the last two. Those viruses are responsible for several diseases in animals and humans. To date, seven $\mathrm{CoV}$ infecting humans have been [4]. In the last two decades, members of the BetaCoV family have been incriminated to cause three epidemics starting with SARS-CoV-1 in 2002, MERS in 2012, and lastly COVID-19 (SARS-CoV-2) in 2019.

Table 1 shows differences between the different etiologies of these three coronaviruses. Severe Acute Respiratory Syndrome (SARS) is a "viral respiratory illness caused by a coronavirus, called SARSassociated coronavirus (SARS-CoV-1)" [5] identified in 2003 [6]. Despite the median age being below 50 years in most countries, SARSCoV-1 affected people of all ages, with a slight female predominance. Around $20.5 \%$ of its cases worldwide were attributed to health care workers [7]. The first SARS-CoV-1 case of atypical pneumonia was reported on November 16, 2002 [8] in Foshan city [9] located in the Guangdong province in southern China [10]. On February 21, 2004, the first case outside China was reported in Hong Kong by a medical doctor who has previously treated patients in Guangzhou, China, and transmitted the disease to 16 guests residing with him in the same hotel. Those ended up spreading the disease into several countries which lead to an international outbreak [11]. From November 2002 till March 2003, several hundreds of people became infected, including health care professionals with the infection cause remaining unknown until March 22, 2003 [9]. That's when SARS-CoV-1 was identified as being the cause of the outbreak in 30 countries leading to 8,422 cases and 916 deaths by July 2003 . At that stage, the associated mortality rate reached $11 \%$ [7]. Since then, WHO declared that the SARS outbreak has been contained worldwide. Since that point, a total of eleven cases were identified till the end of 2004: 7 in Singapore, Taipei, and Beijing and 4 in Guangdong, China [12], no further cases were identified since then [9]. The Middle East Respiratory Syndrome (MERS) is a respiratory disease caused by a coronavirus $(\mathrm{CoV})$ infection. This virus belongs to the Coronaviridae family that causes diseases ranging from the common cold to Severe Acute Respiratory Syndrome (SARS)
$[13,14]$. The characteristics of this type of coronavirus showed a difference in gender infectivity: most cases were males above the age of 60 years who had an underlying medical condition, such as diabetes, hypertension, and renal failure [15]. MERS was first identified in Saudi Arabia in September 2012 in a 60-year-old man who presented with acute pneumonia and subsequent renal failure that led to a fatal outcome $[13,14,16]$. However, a retrospective investigation showed that the earliest identified human cases of MERS were traced back to March 2012, to an acute respiratory illness outbreak in a Jordanian hospital [13,17]. As of 30 June 2019, about 2449 laboratory-confirmed cases and 845 deaths have been reported globally by the WHO [18]. In total, cases from 27 countries in the Middle East, North Africa, Europe, the United States of America, and Asia were declared [18]. The majority of these (84.0\%) were from the Kingdom of Saudi Arabia $[16,18]$. MERS triggered a respiratory illness in the Middle East with a secondary spread in Europe, Africa, Asia, and North America [19]. The infections occurred mainly in the Middle East states (88\%), followed by Asia (11\%), Europe (0.8\%), and the USA (0.1\%) [20]. Nassar MS, et al., [21], reported that the pattern of "MERS infection" has been linked to seasonal variations. Its highest global seasonal occurrence was found during the summer, in June; and, its low occurrence was between October and January. These observations were spread between the years 2012 and 2017 [21]. Saudi Arabia has unique cultural and religious practices, millions of Muslims, internationally, travel to Saudi Arabia seeking Hajj and Umra [21]. According to a recent crosssectional study by Aghazadeh-Attari J, et al., [22], when analyzing the global distribution of MERS, at a worldwide level, one can identify the primary point of spread as being Saudi Arabia, during the period that coincides with the largest annual mass gathering of Muslims in this country to perform Hajj and Umrah rituals.

Besides, the tradition of consuming raw camel milk is observed in Arab countries and has been linked to high occurrence rates of MERS infection [22]. Moreover, authors have found that throughout the years when the MERS was prevalent, the proportion of infected males was significantly higher than that of females. The authors also noticed that most cases were native Saudis, and the infection was more common among those who were at least 50 years of age [22]. One of the reasons why MERS was more observed among this age group is because they were at a greater risk of complications resulting from MERS or any other viral infections, which led them to seek medical care [22]. On the other hand, in Saudi Arabia, men are more likely to spend most of their days outdoors, which puts them at higher risks of exposure to a source of infection [22]. On December 31,2019, several cases of pneumonia of unknown etiology were reported in Wuhan, China. By January 3, 2020, 44 more cases surfaced having the same unknown causal agent. It was only until January 12 when cases began being linked to Wuhan's Huanan Seafood Wholesale Market that trades live animals, including bats [23]. By Jan 31, 2020, 19 countries became infected and 9,826 cases were reported worldwide; as a result, the WHO declared the emerging coronavirus infection as a public health emergency of international concern and proposed measures to control the outbreak [24] (Table 1).

\section{Comparison of the pathogenesis}

Table 2 differentiates the pathogenesis between three coronaviruses that created pandemics in the past years. SARS, a very rare severe acute respiratory syndrome, in general, enters the body as droplets mixing with the respiratory tract mucosa and causing the spread of the virus in the blood [27]. One of the most important receptors for the SARSCoV-2 is the Angiotensin-converting enzyme 2 (ACE2) [27,28]. This type of coronavirus has an incubation period between 2 to 10 days 
Table 1: Comparison of the etiology of SARS-CoV-1, MERS and SARS-CoV-2.

\begin{tabular}{|c|c|c|}
\hline & Etiology & References \\
\hline SARS-CoV-1 & $\begin{array}{l}\text { - } \quad \text { Caused by a coronavirus, called "SARS-associated coronavirus (SARS-CoV-1)" } \\
\text { - } \quad \text { Enveloped, positive-strand RNA virus in the Coronaviridae family }\end{array}$ & $\begin{array}{l}\text { CDC [25] } \\
\text { Gu J, et al. [26] } \\
\text { Pitsiou GG, et al. [27] }\end{array}$ \\
\hline MERS & $\begin{array}{l}\text { - } \quad \text { Caused by a novel coronavirus (Middle East respiratory syndrome coronavirus) } \\
\text { - } \quad \text { Identified in Saudi Arabia in } 2012 \\
\text { - } \quad \text { Zoonotic virus, transmitted originally from animals to people and then among people } \\
\text { - } \quad \text { Mall cases of MERS have been linked to travels to, or residence in countries near the Arabian Peninsula }\end{array}$ & $\begin{array}{l}\text { WHO [15] } \\
\text { CDC [5] }\end{array}$ \\
\hline SARS-CoV-2 & $\begin{array}{l}\text { - } \quad \text { Caused by the SARS-CoV-2 virus } \\
\text { - } \quad \text { Single-stranded RNA viruses, betacoronavirus (betaCoV) } \\
\text { - } \quad \text { Bats and rodents constitute the gene source of betaCoV } \\
\text { - } \quad \text { Cases were linked to Wuhan's Huanan Seafood Wholesale Market }\end{array}$ & $\begin{array}{l}\text { WHO [23] } \\
\text { WHO [24] }\end{array}$ \\
\hline
\end{tabular}

and its risk of transmission is more pronounced during the second week post-infection [29]. It was established after careful observation that for every case of the SARS-CoV-2, 2 to 4 people are expected to get infected [29].

Severe acute respiratory syndrome (SARS-CoV-1) attaches to the angiotensin-converting enzyme 2 (ACE2) in the human body which is expressed on the bronchi and alveoli $[27,28]$. It's highly contagious during the second week of infection [26]. It does not only lead to pulmonary damage; but, the kidneys, intestines, brain, and immune cells can all be affected equally. Multiple mechanisms have been proposed to explain the injuries caused by SARS-CoV-1. Those include genetic factors and abnormalities at the level of the immune response [26]. Its effect is generally delayed for 3 days' post infection. On the other hand, MERS enters the human body by attaching to the DPP4 which is expressed on the bronchi, alveoli, endothelium and immune cells (monocytes derived macrophages) [30,31]. It immediately induces a deleterious effect on the adaptive immune system [30]. Similar to SARS, SARS-CoV-2 enters the human body by attaching itself to the ACE2 receptors and remarkably it can be contagious even in people who are asymptomatic (stage 1 of infection) as opposed to the other two viruses [32-34]. Subsequently the virus travels down the respiratory tract leading to clinical symptoms (stage 2) [35]. However, the virus can follow an aggressive path when it infects the lungs (stage 3 ) infecting pneumocytes type 2 leading to alveolar damage and fibrosis [35]. Mucociliary clearance, as well as innate and adaptive immune response is needed for recovery from this viral infection [35]. To note, the route of transmission of all three viruses is through droplets [5,27].

\section{Comparison of the reservoirs}

Table 3 explains the difference between the reservoirs of the three examined coronaviruses. Researchers report that the new coronavirus SARS-CoV-2 probably got its start in bats, yet another similarity with SARS-CoV-1. Comparing the patients' virus samples with other known types of coronaviruses showed that SARS-CoV-2 is closely related to a coronavirus found in bats, suggesting they are probably the original source of the virus [32,33,36-38]. SARS-CoV-2 shares $96.2 \%$ of its genome with that of $\mathrm{BatCoV}$ [39]. However, WHO indicates that the animal source of SARS-CoV-2 is still unconfirmed yet [40].

\section{Comparison of the clinical findings}

Table 4 overviews the different clinical findings of each of the three examined coronaviruses. Regarding SARS-CoV-1, symptoms include fever, malaise, myalgia, headache, diarrhea and shivering. Although symptoms are not specific for SARS diagnosis, high fever is the most frequent symptom. Dry cough, dyspnea and diarrhea are usually manifested in the first and/or second week of the illness that can lead to a deterioration of cases that may occur rapidly progressing the diseases into a respiratory distress that would be requiring intensive care [6]. Transmission of the virus occurs either directly, from human to human, when droplets (caused from coughs or sneezes) generated from an infected person deposit on the mucous membranes of the mouth, nose or eyes of a nearby person. It can also be transmitted indirectly when a person touches an infected surface contaminated with those droplets and then touches his/her mouth, nose or eyes $[5,41]$. The SARS-CoV-1 virus has resulted in "significant mortality and morbidity worldwide during 2003" and affected the overall health of survivors on both the short and long run [42]. In the early phase following the disease onset, which is normally after 6-7 weeks, SARSCoV-1 survivors were found to have abnormal chest radiographs and abnormal Lactate Dehydrogenase (LDH) levels indicating that patients have not fully recovered yet. Palpitation, exertional dyspnea, malaise, dizziness, depression, myalgia, headache, cough, insomnia and chest discomfort were also noted but results of complete blood counts test, liver and renal functions tests and erythrocyte sedimentation rates were normalized [43]. Six months after illness onset, SARS survivors had impaired health related quality of life $[42,44]$ abnormal chest radiographs, lung function abnormalities [45] and diminished exercise capacity noting that patients admitted to the Intensive Care Unit (ICU) had more deteriorated lung functions than those treated outside the ICU. In addition, avascular necrosis of the hips and knees as well as osteoporosis were found to be common among SARS-CoV-1 survivors where corticosteroids, used in the treatment, could be the major predisposing factor $[46,47]$. The spectrum of SARS-CoV-1 infections ranges from asymptomatic to very severe pneumonia with acute respiratory distress syndrome, septic shock, and multiorgan failure resulting in death $[14,15]$. MERS is a zoonotic virus transmitted between animals and people $[48,49]$. Humans are infected through direct or indirect contact with infected dromedary camels in the Arabian Peninsula [15,48,50]. Azhar EI, et al., [48] showed in a case study, that a dromedary camel was the source of MERS that infected a patient who had close contact with the camel's nasal secretions. However, the virus does not pass easily from person to person unless there is close contact, such as providing unprotected care to an infected patient [15]. Based on the latest WHO summary report, $17.9 \%$ of the total cases reported $(n=2449)$ were health care workers $[14,15]$. A cohort study conducted in Jeddah by Oboho IK, 
Table 2: Comparison of the pathogenesis of SARS-CoV-1, MERS and SARS-CoV-2.

\begin{tabular}{|c|c|c|}
\hline & Pathogenesis & References \\
\hline SARS-CoV-1 & $\begin{array}{l}\text { - } \\
\text { - } \\
\text { - } \\
\text { - } \\
\text { - } \\
\text { - } \\
\text { - } \\
\text { Eisk of of transmiotensing case is expected to infect } 2 \text { to } 4 \text { people } \\
\text { Both abnormal immune responses and injury to immune cells may be key factors in the pathogenesis } \\
\text { of SARS-CoV-1 }\end{array}$ & $\begin{array}{c}\text { Gu J, et al. [26] } \\
\text { Pitsiou GG, et al. [27] }\end{array}$ \\
\hline MERS & $\begin{array}{l}\text { - } \quad \text { DPP4 receptor for MERS } \\
\text { - } \quad \text { Can replicate in human monocyte-derived macrophages (MDMs) } \\
\text { - Induces a substantial cytopathic effect, starting 18-24 h after infection }\end{array}$ & $\begin{array}{l}\text { van den Brand JM, et } \\
\qquad \text { al. [30] } \\
\text { Zheng BJ, et al. [31] }\end{array}$ \\
\hline SARS-CoV-2 & $\begin{array}{l}\text { - } \quad \text { Binds to epithelial cells in the nasal cavity and starts replicating } \\
\text { - } \quad \text { ACE2 is the main receptor } \\
\text { - } \quad 20 \% \text { of the infected patients and will develop pulmonary infiltrates } \\
\text { - The pathological result is diffuse alveolar damage }\end{array}$ & Mason RJ [35] \\
\hline
\end{tabular}

Table 3: Comparison of the reservoirs of SARS-CoV-1, MERS and SARS-CoV-2.

\begin{tabular}{|c|c|c|}
\hline & Reservoirs of Etiology & References \\
\hline SARS-CoV-1 & Certain bat species have been reported as potential natural reservoirs & Gu J, et al. [26] \\
\hline MERS & Current scientific evidence suggests that dromedary camels are a major reservoir host & WHO [15] \\
\hline SARS-CoV-2 & Animal source is still unconfirmed & $\begin{array}{l}\text { Bulut C, et al. [37] } \\
\text { Guo YR, et al. [39] } \\
\text { WHO [40] }\end{array}$ \\
\hline
\end{tabular}

Table 4: Comparison of the clinical findings of SARS-CoV, SARS-CoV-1 and SARS-CoV-2.

\begin{tabular}{|c|c|c|}
\hline & Clinical Findings & References \\
\hline SARS-CoV-1 & $\begin{array}{l}\text { - Symptoms include fever, malaise, myalgia, headache, diarrhea and shivering; high fever is the most } \\
\text { frequent symptom } \\
\text { - Incubation period of 2-10 days } \\
\text { - Severe respiratory illness in the context of a documented exposure risk is the key to diagnosing SARS- } \\
\text { CoV-1 disease } \\
\text { - Laboratory testing include antibody testing using an enzyme immunoassay (EIA) and reverse transcription } \\
\text { polymerase chain reaction (RT-PCR) tests for respiratory, blood, and stool specimens }\end{array}$ & $\begin{array}{l}\text { WHO [6] } \\
\text { CDC [64] }\end{array}$ \\
\hline MERS & $\begin{array}{l}\text { - Typical MERS symptoms include fever, cough and shortness of breath } \\
\text { - } \quad \text { Symptoms start about } 5 \text { days after being exposed to the virus, but can happen up to } 14 \text { days later } \\
\text { Diagnosis is made by healthcare providers asking about medical history, and when you were exposed to } \\
\text { MERS } \\
\text { - Symptoms of MERS can also be caused by other illnesses }\end{array}$ & $\begin{array}{l}\text { WHO [15] } \\
\text { CDC [5] }\end{array}$ \\
\hline SARS-CoV-2 & $\begin{array}{l}\text { - } \quad \text { The incubation period varies between 2-14 days } \\
\text { - } \quad \text { Human to human transmission from droplets and direct contact } \\
\text { - } \quad \text { Transmission can occur during the pre-symptomatic, symptomatic and even asymptomatic phase } \\
\text { - } \quad \text { Early symptoms may include a loss of taste or smell } \\
\text { - } \quad 80 \% \text { of people infected with the virus don't require hospital treatment } \\
\text { - } \quad 20 \% \text { develop serious illness where advanced age and the existence of co-morbidities increase fatality rate }\end{array}$ & $\begin{array}{l}\text { WHO [40] } \\
\text { Sohrabi C, et al [56] } \\
\text { Bulut C, et al. [37] } \\
\text { WHO [57] }\end{array}$ \\
\hline
\end{tabular}

et al., [49] explained that the marked increased number of patients with MERS is due to the increase in secondary human-to-human transmission mainly in health care facilities, rather than by a sudden increase in primary cases in the community (exposure to animals). Authors have found that the vast majority of cases were exposed to other patients with the infection, mostly in health care settings. In addition, another study conducted by Hunter JC, et al., [51] has shown that more than $40 \%$ of all reported infections in Abu Dhabi were in healthcare settings. Additionally, authors have found that healthcareassociated transmission occurred predominantly when HCWs, patients, and visitors were exposed to an infected person before being diagnosed with MERS and implementing the appropriate infection prevention measures. Human-to-human transmission appears to be infrequent outside health care settings but has been documented after 
close household contact with infected persons [52]. A study conducted in Saudi Arabia by Drosten C, et al., [53] has showed that among 280 household contacts evaluated, only $4.3 \%$ had positive results for MERS on real-time Reverse Transcription Polymerase Chain Reaction (RT-PCR) assay or serologic assay. Based on a study conducted by Arwady MA, et al., [54] risk factors responsible for human-tohuman transmission included sleeping in an index patient's room and touching respiratory secretions from an index patient. Very little or no household transmission has been transmission has been detected in other countries in which MERS infections have been reported, and no sustained human-to-human documented in any country to date $[54,55]$. Therefore, these findings underscore the need to strengthen infection prevention and control practices throughout health care facilities [49-51]. The risk factors of MERS are not fully understood, and a definite risk factor in the initial human-to-human or animalto-human transmission has not been confirmed by epidemiological studies yet [22]. According to Aghazadeh-Attari J, et al., [22] findings revealed that two factors, namely, morbid case being native and travel history, are considered significant and remained important as they followed the dynamics of the MERS disease from 2013 to 2016. The incubation period of the SARS-CoV-2 varies from 2 to 14 days [40]. For this virus, the human-to-human transmission from droplets and direct contact is well established. Droplets are generated by an infected person upon coughing, sneezing, or speaking; and, transmission occurs either directly when an individual catches those droplets, or indirectly upon touching the mouth, nose, or eyes after touching infected surfaces [40]. Despite that, the precise mechanism of the virus spread is still debatable and most of the current knowledge is based on similar coronaviruses [56]. Other debatable modes of transmission include airborne and fecal transmissions [37]. It's worthwhile to note that the transmission can occur during the pre-symptomatic, symptomatic and even asymptomatic phase where patients without any symptom can transmit the virus without knowing [57]. The transmission rate
$\left(\mathrm{R}_{0}\right)$ of the virus was estimated to be 1.4-2.5 on January 20, 2020 [58] but higher numbers of 3.28 [59] and 5.7 were reported in more recent studies [60]. Those numbers may be biased because of the different methods in the calculation; therefore, more data is needed to have a more accurate value [37]. The mortality rate of the virus differed among countries; throughout the months, it was about $0.1 \%$ in Qatar, Singapore, and Bahrain; 19.7\% in Yemen as of May 26, 2020, and $5.9 \%$ and $7.7 \%$ in the United States of America (USA) and Canada respectively. This variation is affected by several factors including the number of people tested, demographics, characteristics of the healthcare systems among other unknown factors [61,62]. Symptoms begin to manifest gradually and are usually mild. The most common symptoms include fever, dry cough, and tiredness. Other symptoms include pains, nasal congestion, headaches, sore throat, diarrhea, skin rashes among others [40]. While $80 \%$ of people infected with the virus don't require hospital treatment, $20 \%$ develop a serious illness. The main strains of MERS-CoV-2 showed that advanced age and existing co-morbidities can increase the fatality rate of infected individuals. In Italy, by May 21, 2020, $85 \%$ of deaths related to SARS-CoV-2 were among those aged $>70$ years and $59.6 \%$ of deceased people had three or more comorbidities [63,64].

\section{Comparison of the prevention and treatments}

Table 5 compares the different preventive and possible treatments for the three examined coronaviruses. People with SARS-CoV-1, MERS and SARS-CoV-2 mainly received supportive therapy, with oxygen and fluids to help ease their symptoms. Occasionally, they were prescribed antibiotics to help prevent or treat secondary infections. The CDC recommends avoiding close contact with anyone who is sick or has symptoms; washing hands often with soap and water for at least 20 seconds; using an alcohol-based hand sanitizer that contains at least $60 \%$ alcohol; using disposable tissues instead of hands to cover the mouth when coughing, and throwing tissues away immediately after

Table 5: Comparison of the prevention and treatment of SARS-CoV-1, MERS and SARS-CoV-2.

\begin{tabular}{|c|c|c|}
\hline & Prevention and Treatment & References \\
\hline SARS-CoV-1 & $\begin{array}{l}\text { - } \quad \text { Supportive therapy } \\
\text { - } \quad \text { Aash hands regularly with warm water and soap } \\
\text { - } \quad \text { Use disposable tissues instead of hands to cover the mouth when coughing, and throw tissues away } \\
\text { immediately after use }\end{array}$ & Hopkins [70] \\
\hline MERS & $\begin{array}{ll}\text { - } & \text { Treatment is supportive } \\
\text { - } & \text { Regular hand washing before and after touching animals, and avoid contact with sick animals } \\
\text { - } & \text { Avoid personal contact with sick people } \\
\text { Clean and disinfect frequently touched surfaces and objects }\end{array}$ & $\begin{array}{l}\text { WHO [15] } \\
\text { CDC [72] }\end{array}$ \\
\hline SARS-CoV-2 & $\begin{array}{l}\text { - } \quad \text { Avoid close contact with anyone who is sick or has symptoms } \\
\text { - Wash hands often with soap and water for at least } 20 \text { seconds, or use an alcohol-based hand sanitizer } \\
\text { that contains at least } 60 \% \text { alcohol } \\
\text { - } \quad \text { Cover your face with a cloth face mask in public spaces } \\
\text { - } \quad \text { Avoid touching your eyes, nose and mouth } \\
\text { - } \quad \text { Clean and disinfect high-touch surfaces } \\
\text { - } \quad \text { Stay home and avoid public transportation } \\
\text { - } \quad \text { No cure is available } \\
\text { - The FDA has approved the antiviral drug remdesivir (Veklury) in hospitalized adults and children who are } \\
\text { - } \quad \text { The } 12 \text { and older } \\
\text { (Olumiant) in some case } \\
\text { The FDA has also granted emergency use authorization for convalescent plasma therapy }\end{array}$ & MFMER [71] \\
\hline
\end{tabular}


use; covering the face with a cloth face mask in public spaces; avoid touching the eyes, nose and mouth, cleaning and disinfecting hightouch surfaces; staying home; and, avoiding public transportation. No cure is available for SARS-CoV-2. However, only one medication has been approved to treat this type of novel virus. The FDA approved the antiviral drug Remdesivir (Veklury) to treat SARS-CoV-2 in hospitalized adults and children who are age 12 and older within a hospital setting. It also granted an emergency use authorization for the rheumatoid arthritis drug Baricitinib (Olumiant) to treat the viral infection. Baricitinib is a pill that showed to be effective for reducing inflammation and having antiviral activity. The FDA states that Baricitinib may be used in combination with Remdesivir in people who are hospitalized with SARS-CoV-2 and who are on mechanical ventilators or in need for supplemental oxygen. The emergency use authorization for convalescent plasma therapy to treat this coronavirus type was equally approved by the FDA. Convalescent plasma is blood donated by people recovered from the SARS-CoV-2 infection. It is used to treat people who get hospitalized from SARS-CoV-2.

What was developed for the SARS-CoV-2 that was not successful with the other types of zoonotic coronaviruses are the vaccines. Vaccines are considered to be the number one preventive measure when it comes to infectious diseases Due to the intensive toll this strain of virus had on the world, globally, international attention got directed into saving nations from its heavy burdens. The first SARSCoV-2 vaccine was granted Emergency Use Authorization by the Food and Drug Administration. Another one followed. Both are mRNA vaccines-a new type of vaccine technology [65]. mRNA is a tiny piece of genetic material within the SARS-CoV-2 virus [65]. When SARSCoV-2 mRNA is used in a vaccine, it's engineered and encoded to activate the body's immune system into fighting the coronavirus [65]. mRNA vaccines is considered as instructions on how to make a portion of the "spike protein" that is unique to the SARS-CoV-2. Once displayed on the cell surface, the protein or antigen causes the immune system to begin producing antibodies and activating T-cells fighting off a possible infection. These antibodies are specific to the SARS-CoV-2 virus, which means the immune system becomes primed to protect against future infections [66]. Viruses are simply protein shells that contain either DNA or RNA as their genetic material. In the case of SARS-CoV-2, it is the RNA that is creating the mess. Add to this mess the changes that have been happening to the virus itself that we refer to by mutations. A mutation is a change to one of these nucleotides in the virus's genetic material. In the SARS-CoV-2's case, one of around 30,000 nucleotides is altered but we are starting to observe multiple mutations, which is what is causing high mortality and morbidity in India. Sometimes a mutation in a triplet is silent, meaning the codon still codes for the same amino acid. But even when an amino acid does change, the virus might not behave differently. Some mutations could also spawn dysfunctional viruses that quickly disappear as a result. Certain mutations don't lead to massive alterations in the virus itself which explains why mRNA vaccines will most likely succeed in epidemiologically ending the SARS-CoV-2 pandemic [66]. Studies have reported the acquisition of deletions in the amino (N)-terminal domain (NTD) of the S glycoprotein during long-term infections of often-immunocompromised patients [67-69] [Table 5].

As of 18 February 2021, at least seven different vaccines have been rolled out in countries. Vulnerable populations in all countries are the highest priority for vaccination [73]. Below is a comparison of how each type of vaccine prompts the body to recognize and protect it from the virus that causes COVID-19 that was portrayed in table 6 .
To be fully vaccinated, some SARS-CoV-2 vaccines require two shots [74]. After getting the vaccine that requires two shots, a person is considered fully vaccinated two weeks after the second shot. All the listed vaccines in table 6 require two shots except for Johnson \& Johnson's Janssen COVID-19 vaccine only requires one shot.

\section{Conclusion}

SARS-CoV-1, MERS and SARS-CoV-2 belong to the same beta coronavirus genus. Despite having many similarities in their clinical features, they affected societies differently. There was a big disparity among all three as far the number of cases, deaths, and reproductive rate $\left(R_{0}\right)$. While SARS affected 30 countries and caused 8,422 cases and 916 deaths by the end of the outbreak (SARS Expert Committee, (SARS Expert Committee, 2003), SARS-CoV-2 has affected 217 countries with a total of 5,488,825 cases and 349,095 deaths as of May 27,2020 [75], exceeding by far the number of cases attained by SARSCoV-1 and MERS. SARS-CoV-2 caused 2,519 cases and 866 deaths in 27 countries by January 2020 [40]. The mortality rate of SARS-CoV-2 also differs between countries; since we are still within the outbreak, there is no final mortality rate, but to date this novel virus is found to have a lower mortality rate $(4.4 \%$ as of July 14,2020$)$ [58] than SARSCoV-1 (11\%) (SARS Expert Committee, 2003) and MERS (34.3\%) [40]. Also, SARS-CoV-2 is associated with milder infections due to repetitive mutations in its genes [76]. Similarly, the reproductive rate that is "the number of secondary infections generated from one infected individual" [40] is still controversial and keep varying among countries. Despite these data, it has been concluded that this virus can spread more rapidly in the community than MERS $\left(\mathrm{R}_{0}<1\right)$ and SARSCoV-1 $\left(\mathrm{R}_{0}\right.$ 1.7-1.9) noting that the last two were more associated to nosocomial settings. Due to the lessons obtained from MERS and SARS-CoV-1 and because the world moved at a much faster rate, more efficient preventive measures were taken in hospitals, which led to lower nosocomial infection with SARS-CoV-2 [77]. To date, there is no definitive cure for SARS-CoV-2. Several antiviral therapies, previously used for MERS, SARS-CoV-1, Ebola, malaria, HIV, hepatitis B and C or influenza, are being used urgently on patients infected with the novel virus. Those include nucleoside analogs, chloroquine and protease inhibitors and are still under clinical trials requiring long term studies to avoid unpredictable clinical prognosis. For SARS-CoV-2, research was heavily ongoing accompanied by clinical trials. Different types of vaccines were proposed and examined including DNA vaccine, RNA vaccine, recombinant subunit vaccine in addition to other vaccine approaches [78]. According to the WHO, as of July 28, 2020 a total of 25 candidate vaccines were in clinical evaluation with a total of six vaccines that have reached the phase three [57]. More research is ongoing and different age groups are now being experimented on to widen the eligibility criteria for the vaccination initiatives and attain herd immunity. After long months, several vaccines are validated and expected to help nations reach herd immunity in order to forget about all restrictions and the devastation that this virus inflicted on families. Now, one year following the debut of SARS-CoV-2 in China, countries can be classified into three groups; the first group which has already witnessed the peaks of the pandemic, the second which is in the middle of the peaks, where cases are still reaching peaks; and, the third group that is still somehow experiencing the beginning of an escalation. The lockdown imposed during the first wave of the virus had several consequences at the economic, sociocultural, health and political levels. Now, populations are standing in the midst of a multi-ways roundabout with a few vaccines dominating the roads, hoping that all will lead to one destination: a COVID free life. Despite the amazing results that we are observing, many essential details 
Table 6: Comparison of SARS-CoV-2 (COVID-19) vaccines.

\begin{tabular}{|c|c|c|}
\hline Type of vaccine & Mode of Action & Manufacturer \\
\hline mRNA vaccines & $\begin{array}{l}\text { Contain material from the virus that causes SARS-CoV-2 that gives our cells } \\
\text { instructions for how to make a harmless protein that is unique to the virus. After our } \\
\text { cells make copies of the protein, they destroy the genetic material from the vaccine. } \\
\text { Our bodies recognize that the protein should not be there and build T-lymphocytes } \\
\text { and B-lymphocytes that will remember how to fight the virus in the future. }\end{array}$ & $\begin{array}{l}\text { Pfizer-BioNTech } \\
\text { Moderna } \\
\text { Bayer AG-Germany }\end{array}$ \\
\hline Protein subunit vaccines & $\begin{array}{l}\text { Include harmless pieces (proteins) of the virus that causes SARS-CoV-2 instead of the } \\
\text { entire germ. Once vaccinated, our bodies recognize that the protein should not be } \\
\text { there and build T-lymphocytes and antibodies that will remember how to fight the } \\
\text { virus in the future. }\end{array}$ & $\begin{array}{l}\text { Zhifei Longcom, China } \\
\text { Novavax }\end{array}$ \\
\hline "Whole" virus vaccines & $\begin{array}{l}\text { These vaccines could be: } \\
\text { Inactivated: a version of the virus is inactivated by being exposed to heat, chemicals } \\
\text { or radiation. Or, } \\
\text { Virus-like particle: a version of the virus, closely resembling the real thing, is created } \\
\text { artificially, however it doesn't contain any genetic material, so it's not infectious. } \\
\text { These vaccines cannot cause the disease, but will cause our bodies to produce an } \\
\text { immune response which will protect against future infection. }\end{array}$ & $\begin{array}{l}\text { Sinovac (CoronaVac) (inactivated) } \\
\text { Sinopharm (inactivated) } \\
\text { Bharat Biotech (inactivated) } \\
\text { Medicago Inc. (virus like particle) }\end{array}$ \\
\hline Vector vaccines & $\begin{array}{l}\text { Contain a modified version of a different virus than the one that causes SARS-CoV-2. } \\
\text { Inside the shell of the modified virus, there is material from the virus that causes } \\
\text { SARS-CoV-2. This is called a "viral vector." Once the viral vector is inside our cells, } \\
\text { the genetic material gives cells instructions to make a protein that is unique to the } \\
\text { virus that causes SARS-CoV-2. Using these instructions, our cells make copies of the } \\
\text { protein. This prompts our bodies to build T-lymphocytes and B-lymphocytes that will } \\
\text { remember how to fight that virus in the future. }\end{array}$ & $\begin{array}{l}\text { Oxford-AstraZeneca } \\
\text { Serum Institute of India } \\
\text { Johnson \& Johnson's Janssen } \\
\text { Gamaleya (Sputnik V) }\end{array}$ \\
\hline
\end{tabular}

CDC [74] GAVI [79]

need to be accounted for. On one end, we have Pfizer and Moderna vaccines that offer an above 90 percent protection from complications and mortality against the SARS-CoV-2, the Johnson and Johnson vaccine that offers a 66 percent protection and the Astra-Zeneca that is still banned in a few countries due to the possibility of blood clot formations. While the first two vaccines are offering a protection against the first types of the virus, the Johnson and Johnson also cover the two surfacing variants as well (Brazilian and British). More vaccines are developing and more clinical studies are ongoing to join forces with the international organizations fighting against the SARS-CoV-2. The question that will remain unanswered is how much mutations this virus will keep having and how effective will these new emergency-vaccines be against the flow of ongoing new variants. Now, we are still experiencing some lockdowns. While the USA has been pushing towards an immense mass vaccination that they believe will lead to herd immunity regardless of what is the vaccine that is chosen to be administered, we are still witnessing third waves and total lockdowns in few countries like India, Saudi Arabia, Egypt and many others (Table 6).

Now several countries have lifted their lockdown, eased the measures and opened the airports. Some are negotiating restarting cruising. Restaurants, pubs, night life and gatherings are fully operating as they always did; but, with the absence of a complete populationbased vaccination and the rejection of vaccination among several groups and populations, the fear of more waves caused by variants is real. Individuals as well as national and international organizations should do their best to contain the spread of the virus and avoid more waves. It's still unknown how long the virus will continue and the future is still indefinite [80] but number of cases will still increase as long as the $\mathrm{R}_{0}$ is above 1 . In their report in March 6, 2020, the WHO indicated that $\mathrm{R}_{0}$ was 2-2.5 [40]. In a recent study published in July $2020, \mathrm{R}_{0}$ was still above 1 and ranged 1.2-4.18 [81]. With the high $\mathrm{R}_{0}$ and the incomplete vaccine incorporation, preventive measures including hand washing, social distancing and wearing face masks should be followed [23] to slow down the transmission of the virus until the proper herd immunity is achieved. Now that many nations are returning to normalcy regardless of whether or not they have attained herd immunity, a big question mark remains as to how our coming year will turn out to be. Are we to expect new peaks?

\section{Ethical Statements}

\section{Funding}

There was no funding for this study

\section{Availability of data and materials}

Data are not available in public domain

\section{Conflict of interest}

We declare that there is no conflict of interest

\section{Consent for publication}

We give consent for publication

\section{Ethical approval}

Not applicable

\section{References}

1. Chakraborty H, Bhattacharjya S (2020) Mechanistic insights of host cell fusion of SARS-CoV-1 and SARS-CoV-2 from atomic resolution structure and membrane dynamics. Biophys Chem 265: 106438.

2. Singhal T (2020) A Review of Coronavirus Disease-2019 (SARSCOV-2). Indian J Pediatr 87: 281-286.

3. Worldometer (2021) COVID-19 Coronavirus Pandemic.

4. Cascella M, Rajnik M, Aleem A, Duleboh SC, Di Napoli R (2020) Features, evaluation and treatment coronavirus (SARS-COV-2). StatPearls Publishing. 
5. Centers for Disease Control and Prevention (CDC) (2019) Middle East Respiratory Syndrome (SARS-COV-1).

6. World Health Organization (2012) Severe Acute Respiratory Syndrome (SARS). Geneva, Switzerland.

7. SARS Expert Committee (2003) SARS in Hong Kong: from experience to action. Hong Kong.

8. World Health Organization (2003) Update 95-SARS: Chronology of a serial killer. WHO, Geneva, Switzerland.

9. Hui DSC, Zumla A (2019) Severe Acute Respiratory Syndrome: Historical, Epidemiologic, and Clinical Features. Infect Dis Clin North Am 33: 869-889.

10. Center for disease control and prevention (CDC) (2018) SARS Response Timeline.

11. World Health Organization (2003b) Summary of probable SARS cases with onset of illness from 1 November 2002 to 31 July 2003. Geneva, Switzerland.

12. World Health Organization (2003) The World health report 2003-shaping the future. WHO, Geneva, Switzerland 71-78.

13. Zaki AM, van Boheemen $S$, Bestebroer TM, Osterhaus AD, Fouchier RA (2012) Isolation of a Novel Coronavirus from a Man with Pneumonia in Saudi Arabia. N Engl J Med 367: 1814-1820.

14. Maltezou HC, Tsiodras S (2014) Middle East respiratory syndrome coronavirus: Implications for health care facilities. Am J Infect Control 42: 1261-1265.

15. World Health Organization (2019) WHO MERS Global Summary and Assessment of Risk. Geneva, Switzerland.

16. Oh MD, Park WB, Park SW, Choe PG, Bang JH, et al. (2018) Middle East respiratory syndrome: what we learned from the 2015 outbreak in the Republic of Korea. Korean J Intern Med 33: 233-246.

17. Hijawi B, Abdallat $M$, Sayaydeh A, Alqasrawi S, Haddadin A, et al. (2013) Novel coronavirus infections in Jordan, April 2012: epidemiological findings from a retrospective investigation. East Mediterr Health J 19: S12-S28.

18. World Health Organization (2019) Middle East Respiratory Syndrome Coronavirus (MERS-CoV). WHO, Geneva, Switzerland.

19. Nassar MS, Bakhrebah MA, Meo SA, Alsuabeyl MS, Zaher WA (2018) Middle East Respiratory Syndrome Coronavirus (SARS-COV-1-CoV) infection: epidemiology, pathogenesis and clinical characteristics. Eur Rev Med Pharmacol Sci 22: 4956-4961.

20. Aly M, Elrobh M, Alzayer M, Aljuhani S, Balkhy H (2017) Occurrence of the Middle East Respiratory Syndrome Coronavirus (MERS-CoV) across the Gulf Corporation Council countries: Four years update. PLoS One 12: e0183850.

21. Nassar MS, Bakhrebah MA, Meo SA, Alsuabeyl MS, Zaher WA (2018) Global seasonal occurrence of middle east respiratory syndrome coronavirus (SARS-COV-1-CoV) infection. Eur Rev Med Pharmacol Sci 22: 3913-3918.

22. Aghazadeh-Attari J, Mohebbi I, Mansorian B, Ahmadzadeh J, MirzaAghazadeh-Attari M, et al. (2018) Epidemiological factors and worldwide pattern of Middle East respiratory syndrome coronavirus from 2013 to 2016. Int J Gen Med 11: 121-125.

23. WHO (2020a) Novel Coronavirus (2019-nCoV): Situation Report-1. Geneva, Switzerland.

24. WHO (2020b) Novel Coronavirus (2019-nCoV)-Situation Report 11 Geneva, Switzerland.
25. Centers for Disease Control and Prevention (CDC) (2017) SARS Basics Fact Sheet.

26. Gu J, Korteweg C (2007) Pathology and pathogenesis of severe acute respiratory syndrome. Am J Pathol 170: 1136-1147.

27. Pitsiou GG, Kioumis IP (2020) Severe Acute Respiratory Syndrome (SARS). BMJ Publishing Group.

28. Li W, Moore MJ, Vasilieva N, Sui J, Wong SK, et al. (2003) Angiotensin-converting enzyme 2 is a functional receptor for the SARS coronavirus. Nature 426: 450-454.

29. Peiris JS, Chu CM, Cheng VC, Chan KS, Hung IF, et al. (2003) Clinical progression and viral load in a community outbreak of coronavirusassociated SARS pneumonia: a prospective study. Lancet 361: 17671772.

30. van den Brand JM, Smits SL, Haagmans BL (2015) Pathogenesis of Middle East respiratory syndrome coronavirus. J Pathol 235: 175184.

31. Zheng BJ, Zhou J, Chu H, Li C, Yuen KY (2014) Pathogenesis of active MERS-CoV infection in human macrophages. $4^{\text {th }}$ World Congress on Cell Science \& Stem Cell Research, Conference Proceedings, Valenica, Spain.

32. De Jesus EG (2020) Is the coronavirus mutating? Yes. But here's why you don't need to panic. Science News.

33. Zhou P, Yang XL, Wang XG, Hu B, Zhang L, et al. (2020) A pneumonia outbreak associated with a new coronavirus of probable bat origin. Nature 588: E6.

34. Saey TH (2020) The first case of coronavirus being spread by a person with no symptoms has been found. Science News.

35. Mason RJ (2020) Pathogenesis of COVID-19 from a cell biology perspective. Eur Respir J 55: 2000607.

36. De Jesus EG (2020) SARS and the new coronavirus target the same cellular lock to infect cells.

37. Bulut C, Kato Y (2020) Epidemiology of COVID-19. Turk J Med Sci 50: 563-570.

38. Ge H, Wang X, Yuan X, Xiao G, Wang C, et al. (2020) The epidemiology and clinical information about SARS-COV-2. Eur J Clin Microbiol Infect Dis 39: 1011-1019.

39. Guo YR, Cao QD, Hong ZS, Tan YY, Chen SD, et al. (2020) The origin transmission and clinical therapies on coronavirus disease 2019 (SARS-COV-2) outbreak-an update on the status. Mil Med Res 7: 11.

40. WHO (2020c) Report of the WHO-China joint mission on coronavirus disease 2019 (COVID-19). Geneva, Switzerland.

41. Chan-Yeung M, Xu RH (2003) SARS: epidemiology. Respirology 8: S9S14.

42. Chan JWM, Ng CK (2005) Severe Acute Respiratory Syndrome (SARS): A Brief Review with Exploration of the Outcomes, Prognostic Factors and Sequelae. Curr Respir Med Rev 1: 85-92.

43. Tso EYK, Tsang OTY, Choi KW, Wong TY, So MK, et al. (2004) Persistence of physical symptoms in and abnormal laboratory findings for survivors of severe acute respiratory syndrome. Clin Infect Dis 38: 1338

44. Hui DSC, Wong KT, Antonio GE, Tong M, Chan DP, et al (2009). Longterm sequelae of SARS: physical, neuropsychiatric, and quality-oflife assessment. Hong Kong Med J 8: 21-23.

45. Ng CK, Chan JWM, Kwan TL, To TS, Chan YH, et al. (2004) Six month radiological and physiological outcomes in severe acute respiratory syndrome (SARS) survivors. Thorax 59: 889-891. 
46. Li YM, Wang SX, Gao HS, Wang JG, Wei CS, et al. (2004) Factors of avascular necrosis of femoral head and osteoporosis in SARS patients' convalescence. Zhonghua Yi Xue Za Zhi 84: 1348-1353.

47. Hong N, Du XK (2004) Avascular necrosis of bone in severe acute respiratory syndrome. Clin Radiol 59: 602-608.

48. Azhar El, El-Kafrawy SA, Farraj SA, Hassan AM, Al-Saeed MS, et al. (2014) Evidence for Camel-to-Human Transmission of MERS Coronavirus. N Engl J Med 370: 2499-2505.

49. Oboho IK, Tomczyk SM, Al-Asmari AM, Banjar AA, Al-Mugti $\mathrm{H}$, et al. (2015) 2014 MERS-CoV outbreak in Jeddah--a link to health care facilities. N Engl J Med 372: 846-854.

50. Alsubaie S, Temsah MH, Al-Eyadhy AA, Gossady I, Hasan GM, et al. (2019) Middle East Respiratory Syndrome Coronavirus epidemic impact on healthcare workers' risk perceptions, work and personal lives. J Infect Dev Ctries 13: 920-926.

51. Hunter JC, Nguyen D, Aden B, Al Bandar Z, Al Dhaheri W, et al. (2016) Transmission of Middle East Respiratory Syndrome Coronavirus Infections in Healthcare Settings, Abu Dhabi. Emerg Infect Dis 22: 647-656.

52. Arabi YM, Balkhy HH, Hayden FG, Bouchama A, Luke T, et al. (2017) Middle East Respiratory Syndrome. N Engl J Med 376: 584-594.

53. Drosten C, Meyer B, Müller MA, Corman VM, Al-Masri M, et al. (2014) Transmission of MERS-Coronavirus in Household Contacts. N Engl J Med 371: 828-835.

54. Arwady MA, Alraddadi B, Basler C, Azhar El, Abuelzein E, et al. (2016) Middle East Respiratory Syndrome Coronavirus Transmission in Extended Family, Saudi Arabia, 2014. Emerg Infect Dis 22: 13951402.

55. Kraaij-Dirkzwager M, Timen A, Dirksen K, Gelinck L, Leyten E, et al. (2014) Middle East respiratory syndrome coronavirus (SARS-COV-1CoV) infections in two returning travellers in the Netherlands, May 2014. Euro Surveill 19: 20817.

56. Sohrabi C, Alsafi Z, O'Neill N, Khan M, Kerwan A, et al. (2020) World Health Organization declares global emergency: A review of the 2019 novel coronavirus (SARS-COV-2). Int J Surg 76: 71-76.

57. WHO (2020d) Coronavirus disease 2019 (COVID-19): Situation Report-73. Geneva, Switzerland.

58. WHO (2020e) Statement on the first meeting of the international health regulations (2005) emergency committee regarding the outbreak of novel coronavirus 2019 (n-CoV). Geneva, Switzerland.

59. Liu Y, Gayle AA, Wilder-Smith A, Rocklov J (2020) The reproductive number of SARS-COV-2 is higher compared to SARS coronavirus. $J$ Travel Med 27.

60. Sanche S, Lin YT, Xu C, Romero-Severson E, Hengartner N, et al. (2020) High contagiousness and rapid spread of severe acute respiratory syndrome Coronavirus 2. Emerg Infect Dis 26: 1470-1477.

61. John Hopkins University and Medicine (2020a) Mortality analyses.

62. Johns Hopkins University (2020b) SARS-COV-2 dashboard by the center for systems science and engineering (CSSE) at Johns Hopkins University.
63. Epicentro (2020) Characteristics of SARS-CoV-2 patients dying in italy report based on available data on May 21 2020.

64. Centers for Disease Control and Prevention (CDC) (2005) In the Absence of SARS-CoV Transmission Worldwide: Guidance for Surveillance, Clinical and Laboratory Evaluation, and Reporting.

65. Stappenbeck T (2020) How SARS-COV-2 MRNA Vaccines Work.

66. Centers for Disease Control and Prevention (CDC) (2020) Clinical Considerations for COVID-19 Vaccination.

67. McCarthy KR, Rennick LJ, Nambulli S, Robinson-McCarthy LR, Bain WG, et al. (2021) Recurrent deletions in the SARS-CoV-2 spike glycoprotein drive antibody escape. Science 371: 1139-1142.

68. Avanzato VA, Matson MJ, Seifert SN, Pryce R, Williamson BN, et al. (2020) Case study: Prolonged infectious SARS-CoV-2 shedding from an asymptomatic immunocompromised individual with cancer. Case Reports 183: 1901-1912.

69. Chi X, Yan R, Zhang J, Zhang G, Zhang Y, et al. (2020) A neutralizing human antibody binds to the $\mathrm{N}$-terminal domain of the Spike protein of SARS-COV-2. Science 369: 650-655.

70. John Hopkins Medicine (2021) Severe Acute Respiratory Syndrome (SARS).

71. Mayo Foundation for Medical Education and Research (MFMER) (2020) Coronavirus disease 2019 (SARS-COV-2). Mayo Clinic.

72. Centers for Disease Control and Prevention (CDC) (2019) MERS Transmission. USA.

73. Centers for Disease Control and Prevention (CDC) (2021) Understanding How COVID-19 Vaccines Work.

74. Centers for Disease Control and Prevention (CDC) (2021) COVID-19 Vaccines that Require 2 Shots.

75. WHO (2020f) Coronavirus disease (COVID-19): Situation Report-128. Geneva, Switzerland.

76. Benvenuto $D$, Giovanetti $M$, Ciccozzi $A$, Spoto $S$, Angeletti $S$, et al. (2020) The 2019-new coronavirus epidemic: Evidence for virus evolution. J Med Virol 92: 455-459.

77. Petrosillo N, Viceconte G, Ergonul O, Ippolito G, Petersen E (2020) COVID-19, SARS and MERS: Are they closely related? Clin Microbiol Infect 26: 729-734.

78. Ahn DG, Shin HJ, Kim MH, Lee S, Kim HS, et al. (2020) Current status of epidemiology, diagnosis, therapeutics, and vaccines for novel coronavirus disease 2019 (COVID-19). J Microbiol Biotechnol 30: 313-324.

79. Gavi (2021) There are four types of COVID-19 vaccines: here's how they work.

80. Ali I (2020) COVID-19: Are we ready for the second wave?. Disaster Med Public Health Prep 14: e16-e18.

81. Hilton J, Keeling MJ (2020) Estimation of country-level basic reproductive ratios for novel coronavirus (SARS-CoV-2/SARS-COV-2) using synthetic contact matrices. PLOS Computational Biology 16. 